Clinical Practice \& Epidemiology in
CrossMark
Mental Health
Content list available at: www.benthamopen.com/CPEMH/
DOI: $10.2174 / 1745017901612010120$

REVIEW ARTICLE

\title{
From Asperger's Autistischen Psychopathen to DSM-5 Autism Spectrum Disorder and Beyond: A Subthreshold Autism Spectrum Model
}

Liliana Dell'Osso ${ }^{a}$, Riccardo Dalle Luche ${ }^{\mathrm{a}}$, Camilla Gesi ${ }^{*}$,, Ilenia Moroni ${ }^{\mathrm{a}}$, Claudia Carmassi ${ }^{\mathrm{a}}$ and Mario Maj ${ }^{\mathrm{b}}$

${ }^{a}$ Department of Clinical and Experimental Medicine, University of Pisa, via Roma 67, 56100 Pisa, Italy

${ }^{b}$ Department of Psychiatry, University of Naples SUN, Largo Madonna delle Grazie 1, 80138 Naples, Italy

Received: February 02, 2016

Revised: August 27, 2016

Accepted: August 27, 2016

\begin{abstract}
Growing interest has recently been devoted to partial forms of autism, lying at the diagnostic boundaries of those conditions previously diagnosed as Asperger's Disorder. This latter includes an important retrieval of the European classical psychopathological concepts of adult autism to which Hans Asperger referred in his work. Based on the review of Asperger's Autistische Psychopathie, from first descriptions through the DSM-IV Asperger's Disorder and up to the recent DSM-5 Autism Spectrum Disorder, the paper aims to propose a Subthreshold Autism Spectrum Model that encompasses not only threshold-level manifestations but also mild/atypical symptoms, gender-specific features, behavioral manifestations and personality traits associated with Autism Spectrum Disorder. This model includes, but is not limited to, the so-called broad autism phenotype spanning across the general population that does not fully meet Autism Spectrum Disorder criteria. From this perspective, we propose a subthreshold autism as a unique psychological/behavioral model for research that could help to understand the neurodevelopmental trajectories leading from autistic traits to a broad range of mental disorders.
\end{abstract}

Keywords: Asperger's disorder, AdAS spectrum, Autism spectrum disorder, DSM-5, Neuroatypicality, Subthreshold autism spectrum.

\section{INTRODUCTION}

Little interest has been hitherto devoted to adult courses of mild autistic forms, particularly those with normal or above the average intelligence, that usually remain undiagnosed or misdiagnosed upon the common assumption that autism is associated with intellectual and language disability as well as to severe impairment in social interactions. Previously ascribable to Asperger's Disorder (AD) [1], these cases are currently encompassed into DSM-5 Autism Spectrum Disorder (ASD) [2]. However, neurodevelopmental disorders, specifically ASD, have undergone considerable diagnostic evolution in the past decade, leading not only to relevant similarities and differences with the worldwide adopted criteria of the the International Statistical Classification of Diseases and Related Health Problems, Tenth Revision (ICD-10), adopted in the general medical system, but also corroborating the need for alternative diagnostic approaches, such as that proposed by the initiative termed Research Domain Criteria (RDoC) [3, 4]. This latter, in fact, intends to shift the focus of research, and eventually clinical practice, away from existing diagnostic categories, as recently updated in the DSM-5, towards 'new ways of classifying psychopathology based on dimensions of observable behavior and neurobiological measures', thus linking symptom domains to underlying biological and neurological mechanisms.

\footnotetext{
* Address correspondence to this author at the Department of Clinical and Experimental Medicine, Section of Psychiatry, University of Pisa, via Roma 67, 56100 Pisa, Italy; Tel: +39 340860 2160; Fax: +39 05022 19 787; E-mail: camillagesi@hotmail.com
} 
Parallel, growing evidence suggests that the adult course of mild autistic forms is frequently complicated by other mental disorders, including Anxiety, Mood, Psychotic and Trauma and Stressor-related Disorders, so that these patients may receive clinical attention for the onset of these disorders while their autistic features may remain unrecognized [5]. Alternatively, these forms might also arguably be misdiagnosed as a wide range of personality disorders (e.g., Borderline, Schizoid, Schizotypal, Avoidant, Dependent), the core symptoms being the impairment of interpersonal and empathic functions.

In the light of these considerations, the aim of the present paper is, first of all, to review the historical evolution of Hans Asperger's Autistischen Psychopathie starting from his first descriptions through the DSM-IV AD and up to the recent DSM-5 ASD. Further, accounting most recent literature focusing on autistic like features and traits and broader autism phenotype, we highlight the limits of current DSM-5 diagnostic approach proposing the potential usefulness of a Subthreshold Autism Spectrum Model, which explores autistic features by using a dimensional approach that also takes into account sub-threshold, atypical and gender-specific features, as well as personality traits, and which may more accurately describe the above mentioned cases [6]. This model has been developed in line with the work of an international Italy-USA research project (termed Spectrum Project and started in 1995), that has developed a Spectrum Model approach to mental disorders [7, 8] evaluating criterion and non-criterion symptoms and signs, behavioral manifestations, subthreshold or atypical features, or temperamental traits associated with a specific mental disorder and that has been shown to be particularly appropriate for understanding the clinical features, course and comorbidity of most mental disorders, as well as the continuity between the general and the clinical population. Eventually, upon the neurodevelopmental perspective recently suggested $[9,10]$, we argue that such autistic dimension may underlie and favor most mental disorders and be the expression of a psychopathological liability [6].

\section{Autistische Psychopathie According to Hans Asperger}

In 1943, the Austrian pediatrician Hans Asperger described some children with deficient non-verbal communication skills, lack of empathy with peers, physical clumsiness, sometimes associated to exceptional skills or talent [11]. Differently from the contemporary Kanner's contribution on severe autism [12, 13], Asperger's work remained mostly ignored until its first English translation, in 1981 [14]. Thereafter, the syndrome was named after Asperger [15] and was eventually included in the DSM-IV as AD [1].

According to Asperger's descriptions, the verbal communication of these patients is usually formally normal, while the content tends to be pedantic and often consists of disquisitions on favorite subjects. The young adult generally lacks a sense of humor and does not understand jokes, especially those targeting him. Non-verbal communication is compromised as well: when talking to others these subjects usually avoid eye-to-eye contact and it is hard to detect whether their look is lost in the distance, or whether it is lost inwardly. Concomitantly, a paucity of facial and gestural expression and flat, emotionally toneless language, not directed to the addressee but often into empty space, are noted in these subjects. Because of the lack of interpersonal competence, since childhood these subjects avoid social contacts, often showing school maladjustment, conflicts with their family, teachers and peers, loneliness and isolation. Whether they are only children or have siblings, they often behave like strangers in their families. Asperger described as a clue of their interpersonal deficit the so-called autistic malice, that is to say hurting behaviors toward others that are enacted without awareness of the physical or psychological harm they may cause [15]. Other conflicts arise from their parents' expectation that these children might naturally learn from empathic mechanisms, while they only learn by following rules or imitating other people. When straining to join the group of peers, these subjects are often ridiculed because of their awkwardness and they are likely to be the targets of bullying episodes or marginalization, becoming, in consequence, anxious and afraid. At school, however, they may be in some cases accepted as eccentric "professors", and respected for their selective, unusual abilities [14]. AD subjects often show sensory disturbances, including altered perception to food, sound and clothing. Personal hygiene is precarious because contact with water is refused or other experiences, such us cutting nails, are sensed as unpleasant. On the positive side, Asperger's description pointed out how disabilities were closely interwoven with special abilities such as exceptional memory, unusual interest in natural sciences, mental calculations skills, inclination to abstraction (good premise for scientific performance). Somehow consistently, Asperger also highlighted the fact that many patients' ancestors showed good social functioning and gained prominent positions and intellectual achievements.

Asperger believed that the syndrome was never recognized in infancy (usually much later than the third year of life). Moreover, he pointed out that while little girls with autism are uncommon, mothers of autistic children with traits of coldness and lack of empathy are the rule, assuming that females could develop autistic traits only after puberty. 
Both Kanner and Asperger referred to Eugen Bleuler's concept of autism [16] with the former considering infantile autism as a form of early schizophrenia and the latter as a form of psychopathic personality. Interestingly, Bleuler considered autism not only as a core symptom of schizophrenia but also as a dimension spanning across a wide range of non-schizophrenic conditions including superstition and pseudoscience [17]. Similarly, Asperger seemed to suggest a spectrum perspective while pointing out that the capacity to withdraw into an inner world of one's own special interests is available in a greater or lesser measure to all human beings. Moreover, he emphasized that this ability has to be present to a marked extent in those who are creative artists or scientists. On such basis, while wondering whether autistischen psychopathie could represent a partial schizophrenic predisposition, Asperger highlighted the stability of the clinical picture throughout childhood, adolescence and at least early adulthood and the good social prognosis, meaning that most individuals were able to use their special skills to obtain employment and that some who had especially high levels of ability were able to follow careers in, for example, science and mathematics [14].

\section{AD Rise and Fall, from DSM-IV to DSM-5}

DSM-IV AD [1] doesn't fully overlap with Asperger's psychopathy, especially because it lacks some subtle descriptions [14] and does not account for the selective and special skills that may contribute to the high achievements in adult life. Moreover, constrained within the boundaries of Developmental Disorders, the DSM-IV AD does not provide an accurate picture of possible adult pathways. The differential diagnosis must be posed especially with regard to Obsessive-Compulsive Disorder (OCD) and Schizophrenia. In AD, rumination is usually ego-syntonic and the social impairment more severe compared to OCD. On the contrary, AD-associated impairment of social interaction and restricted interests are less pervasive compared to Schizophrenia. As far as personality disorders are concerned, the distinction with Schizoid Personality Disorder is one of the most challenging, but, usually, AD shows greater severity and earlier onset.

After the DSM-IV inclusion as a distinct category, AD gained an unusual mediagenic celebrity. Many people qualified themselves for $\mathrm{AD}$, building up internet sites and blogs, and a great number of leaders, artists and geniuses was posthumously claimed to be Aspergers [18 - 21] such that, while most psychiatric patients had to cope with the stigma of mental illness, subjects with AD ended up dealing with the aura of being Aspergers. On such bases, the concept of $\mathrm{AD}$ was manipulated by the mass-media to label all those geniuses who have stood out for their cognitive peculiarities and original thought, but also for an unexpected history of poor school performance, developmental delays, tendency to isolation, phobias and social phobias, awkwardness, obsessions and ruminations. These personality traits, in fact, seem quite common in mathematicians and physicists boasting outstanding intellectual abilities [20, 22, 23].

Many attempts have been made to define the peculiar neurocognitive abilities of these subjects, such as high perceptual sensitivity, attention to details, and lack of sense of central coherence [24]. Fitzgerald and colleagues [23] defined the Asperger savantism, which is related to true creativity, as opposed to the autistic savantism, that has no practical aim. Baron-Cohen and colleagues [25] highlighted the ability of systematization, described as the accumulation of facts or measures about the physical world in a systematic way. Lyons and Fitzgerald pointed out that individuals with AD show great attention-focusing abilities, accuracy in perceiving details, increased memory, and restricted interests [26]. More recent clinical studies, however, found a lower speed in test performances of AD children compared to typically developing subjects with the same intelligence quotient [27].

The great number of studies following the inclusion of $\mathrm{AD}$ in the DSM-IV failed to differentiate it from Kanner autism (which is associated with intellectual disability in $80 \%$ of cases). The distinctiveness of AD from "Highfunctioning autism" (HFA) has been questioned as well [14, 27 - 33]. Thus, AD and autism, that is to say Asperger's and Kanner's autisms, have been unified in the DSM-5, as different degrees of severity of the same spectrum of disorders [34]. The diagnosis of AD was, in fact, incorporated into the category of ASD together with Pervasive Developmental Disorder and Childhood Disintegrative Disorder, thus AD disappeared as a distinct category.

Within DSM-5 ASD diagnosis, individual clinical characteristics are noted through the use of specifiers (e.g., intellectual impairment, language impairment) so that individuals with AD would now receive a diagnosis of ASD without language and intellectual impairment [2]. However, more subtle characteristics in the nature of social interaction, motor skills and speech patterns that since Asperger's first description have differentiated AD from autism, are not acknowledged in the new DSM-5 ASD criteria [35]. Positive aspects of autism, such as savant skills, are neglected as well [36]. Further, although current impairment is required to make a diagnosis, the DSM-5 warns that diagnostic criteria may be met even if only based on historical information. Symptoms, in fact, may change through development stages and may be masked by compensatory and even hyper-compensatory mechanisms. Besides losing 
the distinctiveness of AD, some studies raised the concern that DSM-5 criteria may be more stringent than those of DSM-IV, so that some individuals previously diagnosed as AD will lose out [36 - 41]. These subjects may end up falling into the new category of 'Social Communication Disorder' [42, 43] that includes those subjects who do not show repetitive behaviors and restricted interests, but who do have social communication impairment interfering with academic and occupational performances. On the other hand, the reduced sensitivity of DSM-5 criteria might increase the proportion of subjects receiving a delayed diagnosis of AD. Adults with pure AD, in fact, very rarely seek clinical attention. Their search for treatment is essentially related to the onset of comorbid mental disorders, such as anxiety, mood or eating disorders, acute or chronic psychoses, suicidal ideation or self-injuring behaviors, or because of issues related to a worsening of social impairment after the loss of caregivers, or to forensic controversies upon illegal behaviors [44 - 46]. Recent literature, however, reports that psychiatrists rarely identify these subjects with a correct ASD diagnosis when facing them in their daily practice $[47,48]$.

A further important issue, raised by recent epidemiological and genetic studies and disregarded by the DSM-5, is the clinical and etiological continuity between ASD diagnosis and autistic traits in nonclinical populations [45 - 54]. Autistic traits are conceptualized as both cardinal and associated features of ASD, such as subthreshold social and communication deficits, unusual personality features and stereotyped behaviors, continuously distributed in the general population and used to characterize the Broad Autism Phenotype, frequently found among relatives of people with autism [55 - 61]. For example, high rates of these symptoms were found in members of families with multiple-incidence autism, as well as phenotypically expressed genetic risks and empathy deficits were reported in fathers of autistic children [62 - 66].

\section{ASD, Cluster A Personality Disorders and Schizophrenia}

Since first descriptions, the Autistischen Psychopathie was supposed to have a role in the search for precursors and early symptoms of schizophrenia [7]. Later clinical and epidemiological studies have demonstrated high prevalence rates of psychotic disorders among subjects with ASD [67 - 70] posing the question whether autism may represent either a risk factor for psychosis or the early stage of it [71]. On the other hand, doubts have been raised on the validity of the concept of comorbidity that may merely depend on the artificiality of current diagnostic boundaries [72, 73]. The exclusion of "autism" from diagnostic criteria for Schizophrenia, adopted by the DSM-III [74] and handed down to later editions, was based on the lack of its operative reliability. As a consequence, only paranoid or disorganized subtypes of Schizophrenia have been diagnosed across the different DSM editions, ignoring the broad European tradition that identified the fundamental symptoms, the quiddity of the disease [75], in nonspecific symptoms that affect social and empathic skills, special and idiosyncratic cognitive forms of thought and pragmatic deficit. Such clusters of features correspond to the fundamental symptoms of the Bleulerian Group of Schizophrenias (autism, ambivalence, associative disorders and emotional-affective disorders) [16], the core features of Minkowski's concept of schizophrenia (lack of attunement and vital contact with reality) [76], the concept of "autism" as the crisis of common sense and lack of naturalness and obviousness of Blankenburg [77] and Parnas [78, 79]. The relationship between autistic traits and schizophrenia, either premorbid or featuring its chronic course, has been largely overlooked after the changes encoded in DSM-III criteria. The link between autism and schizophrenia has survived in other models, such as the Bonn School concept of Basic Symptoms of Schizophrenia [80]. These latter can be assessed both in premorbid and in chronic forms and include the subjectively perceived disorders of interpersonal contact and the elementary disturbances of thought and emotional regulation, with which the patient copes with compensatory strategies and behaviors.

Along with the exclusion of autism from the DSM-III diagnostic criteria, marginal forms of Schizophrenia, characterized by severe and chronic depersonalization, isolation, and social disability but not by positive symptoms, ended up spreading across a broad range of personality disorders, particularly Schizoid and Schizotypal, but also Borderline Personality Disorder [81, 82]. As acknowledged by the DSM-5, the differential diagnosis between ASD and Schizoid or Schizotypal Personality Disorders is difficult for both the overlapping diagnostic criteria and the similar age of onset and course. However, according to DSM-5, Schizoid and Schizotypal Personality Disorders should be diagnosed only if symptoms do not occur exclusively during the course of ASD [42]. Thus, these clinical entities, excluded as autistic symptoms from Schizophrenia and thereafter diagnosed as Schizoid and Schizotypal Personality Disorders, are likely to be diagnosed as ASD according to DSM-5 guidelines. The issue of the distinction between ASD, cluster A Personality Disorders, early/undiagnosed forms of Schizophrenia would thus appear the result of a diagnostic artifact related to the nosological system instead of it most likely being the expression of a phenomenological continuum. 


\section{The Subthrehsold Autism Spectrum Model}

Within the framework of an international Italy-USA research project (Spectrum Project), started in 1995 and involving the Department of Psychiatry of the University of Pisa along with the Universities of Pittsburgh, Columbia New York and California San Diego, a Spectrum Model approach to mental disorders has been developed [7, 8]. Such model has been shown to be particularly appropriate for understanding the clinical features, course and comorbidity of most mental disorders, as well as the continuity between the general and the clinical population. The Spectrum instruments comprise a set of structured clinical interviews and self-report questionnaires that evaluate the lifetime occurrence of DSM criterion and non-criterion symptoms, behavioral manifestations, subthreshold or atypical features, or temperamental traits associated with a specific mental disorder, that may occur before, during or after the onset of a full-blown DSM disorder, but that may also be present in subjects who do not fulfill the diagnostic threshold. Spectrum manifestations may comprise early onset precursors, prodromal features of onset or recurrence, or persistent residual symptoms, as well as personality traits, independently from their interference with the overall functioning and quality of life $[8,81-90]$.

Such a spectrum model is consistent with the alternative, dimensional approach proposed by the DSM-5 for personality disorders (Section III-Emerging Measures and Models). According to this model, personality disorders represent maladaptive variants of personality traits that merge imperceptibly into normality and into one another, as well as spectra of personality dysfunctions on a continuum with other mental disorders [2]. Differently, the concept of spectrum applied by DSM-5 to autism, besides lacking some of the important features first described by Asperger in his patients, does not take into account more subtle dimensional phenomena as the Broad Autism Phenotype or the subthreshold autism spectrum running in the general population who partially meet criteria for ASD [49]. We argue instead that the conceptualization of autism as $a$ spectrum should not only refer to the dimensional nature of the core features of autism within the clinical population (i.e., differences in the severity of symptoms among those with a diagnosis of ASD), as conceptualized by the DSM-5, but could also be interpreted as the continuity between the clinical and the general population [7, 43]. Asperger himself pointed out that the features that characterize the Autistischen Psychopathen can be found in varying degrees in the general population [14]. Accordingly, we propose a subthreshold Autism Spectrum that explores autistic features by using a dimensional approach focusing on subthreshold, atypical and gender-specific features, as well as personality traits [6]. From this perspective, we developed the AdAS Spectrum questionnaire that explores the whole spectrum of manifestations of autism, including, but not limited to, the former DSM-IV diagnosis of $\mathrm{AD}$, as well as some intermediate phenotypes lying at the boundaries of ASD and characterized by subthreshold to mild autism spectrum symptoms [91].

Adults with subthreshold to mild autism usually present difficulties in integrating in groups and building relationships with other people, showing a tendency to avoid and withdraw from them. Sometimes they find it easier to establish relationships with much younger or older people; often they may prefer to spend time with pets, to which they show strong attachment and that they are likely to anthropomorphize. Internet may be the preferred communication instrument that helps these subjects to build relationships and keep in touch with a few special friends, who share their restricted and specific interests. Sometimes they have imaginary companions with whom they have solipsistic dialogues, but they may also talk to themselves, asking and answering questions. When talking to others, they may refer to themselves using the third person. From infancy onwards, these subject do not seek and may even avoid cuddling and regard physical contact as unpleasant. They avoid or barely tolerate sharing spaces with others, they are unnatural in social contexts, and naive in interpersonal relationships. They often show paradoxical empathy (coldness/hyperengagement) leading to misunderstandings or unmet expectations about social interactions that may be very frustrating. As a consequence, they may develop compensatory mechanisms such as emulating, imitating others, in order to integrate with them. Alternatively, they sometimes draw attention to themselves for acting bizarrely, or because of their manneristic appearance, look or expressions. They may have no friends who can provide advice on dating and on social and sexual codes and they may use television programs and films as source material to learn about relationships, despite often being unable to translate these latter into every day life in order to start or maintain relationships. Such misunderstandings could make them avoidant of intimate relationships or, conversely vulnerable to promiscuity or being charged of sexually inappropriate behaviors [92 - 94].

In spite of normal or above normal intellectual abilities, the deficits in communication and social interaction shown by these subjects may cause significant impairment in academic performance. For this reason these subjects may leave school early or pursue self-education, often being self-taught learners. They also usually show meta-linguistic deficits, meaning that the comprehension of symbols, simulations, humor, idioms, jokes, metaphors and other figures of speech 
may be difficult. However, they may involuntarily appear funny by using neologisms or peculiar language patterns and sense of humor. In some cases, cognitive deficits may be more severe, including dyslexia and dyscalculia, or be associated with Attention Deficit Hyperactivity Disorders (ADHD). In this regards, recent research and the RDoC initiative are recognizing considerable overlap in the clinical presentation of ASD and ADHD, that are regarded instead as distinct disorders in the current DSM-5, and interesting preliminary neuroimaging findings are supporting these new hypotheses [95]. In other cases, cognitive and pragmatic deficits in everyday activities, such as house cleaning, preparing meals, driving, may be associated with unconventional and creative thinking, that leads to outstanding performances in restricted fields.

Proneness to pseudo-obsessions and rumination is typical and mostly useless, due to the impaired ability in understanding another's point of view. Since they usually have a hard time understanding what people think or are going to do, they prefer disciplined, predictable circumstances; since systems usually follow rules, which make them predictable, they tend to systematize everything, sorting things (as well as people) into categories and writing lists [96]. An excessive, pointless perfectionism may result from their great attention to details, while the refined perfection of some creative work may represent the bright side of it. They may be excessively attached to objects, some of which may be inappropriate for their age (e.g., stuffed animals) or worn out, to the point that they may want to carry them all the time or constantly check to make sure that they are in place. Frequently, they are hoarders of useless objects. Besides having strong aversions to some tastes and textures that lead to extreme food selectivity, they may show a rigid, inflexible attitude in eating behaviors, such that dietary choices and food intake often tend to be systematized as well.

The DSM-5 acknowledges that, even when gaining high functioning levels, these subjects remain socially naive and vulnerable, and are prone to anxiety and depression [2]. A recent review of available data confirms that ASD subjects show high rates of comorbidity with other Axis I disorders, in which mood and anxiety disorders are the most frequent diagnoses in the majority of the studies [46]. Specifically, two studies conducted among ASD adults with normal intelligence found prevalence estimates of depression of 53\% and 70\% respectively [97, 98]. The same studies reported quite a high prevalence of anxiety disorders, with estimates ranging from $15 \%$ to $22 \%$ for generalized anxiety disorder and from $13 \%$ to $22 \%$ for social anxiety disorder. As for psychotic disorders, comorbidity rates with ASD range from $4.4 \%$ to $18 \%$ in the general population $[67,68]$ and between $7 \%$ and $16 \%$ in clinical samples [69, 70]. Finally, approximately $50 \%$ of individuals with AD have been found to meet criteria for a personality disorder [98].

However, other authors have shown that the overlap between ASD and other mental disorders might be even wider than previously reported, highlighting the fact that mild forms may be concealed by other mental disorders. A $16 \%$ ASD prevalence rate, in fact, has been found among first-visit depressed adult patients, indicating that ASD is likely to be overlooked unless specifically investigated, especially in subjects with normal intelligence and moderate autistic forms [5]. Similarly, recent evidence also suggests rates as high as $7.3 \%$ of previously unrecognized ASD among suicide attempters hospitalized for inpatient treatment [47]. Further, girls with anorexia have been shown to have higher levels of autistic traits than controls, leading to the hypothesis that a proportion of females with autism may be being overlooked or misdiagnosed, because they present to clinics with eating disorders [99, 100].

\section{DISCUSSION}

\section{Limitations of Current Research}

Most recent research indicates that subjects with mild forms of ASD often come to clinical attention only during late adolescence or adulthood, prompted by the onset of other mental disorders. This may pose great challenge to diagnostic process $[101,102]$ and raise the risk of misdiagnosis [5, 47, 103]. This is likely the case of ASD subjects with Mood Disorders misdiagnosed as psychotics for the atypical symptoms and the peculiar patterns of behavior related to their ASD [104]. Similarly, King [105] suggested that ASD patients with comorbid complex Post Traumatic Stress Disorder (PTSD) are often diagnosed as suffering from Borderline Personality Disorder, with ASD remaining unrecognized.

Since it has been demonstrated that autistic dimension is continuously distributed from the clinical to the general population, we may hypothesize that partial forms of ASD, referred to as "autistic traits", pose a greater vulnerability to psychopathology as well. However, there is a lack of prospective studies investigating the long-term evolution of autistic traits in non-clinical populations.

Parallel, despite some recently emerging classification systems [3, 4], neurobiological research still needs to move away from dichotomous diagnosis (affected/not affected) and to find a system based on psychological and behavioral dimensions, regardless of what is or is not considered a disease. 


\section{Perspectives for Future Research}

The subthreshold autism spectrum model we suggest is meant to encompass both threshold- and subthreshold-level manifestations of autism, with a focus on mild and atypical symptoms, behavioral features and personality traits. These manifestations may, or may not, have a significant impact on subject's functioning [99], also encompassing some positive aspects of neuroatypicality, such as divergent and creative thinking $[6,25,106]$.

Despite not included among ASD, the subthreshold autism spectrum could be crucial in detecting the autistic matrix underlying several mental disorders. In fact, it may allow to sketch individual profiles, helping to unravel which autistic dimensions predispose to the high comorbidity between ASD and those psychiatric conditions emerging to be associated with it and enabling clinicians to more accurately define the physiopathology, course and treatment response of such mental disorders [6].

In the light of a coherent model of illness, rooted in brain development, anatomy and functioning, we will be able to rethink Asperger's work, overcoming the issue whether what was previously referred to as Asperger's Disorder, and currently encompassed into the DSM-5 ASD, is a stable personality trait, a premorbid state linked to schizophrenia, or a nonspecific vulnerability factor for other mental disorders. From this perspective, we propose subthreshold autism as a unique psychological/behavioral model for research, that could help to understand the neurodevelopmental trajectories leading to from autistic traits to a broad range of conditions, such as schizophrenia, mood and personality disorders, but also to the normal, individual variability in cognition, mood, and personality. Protocols specifically tailored to explore such spectrum model will help to understand the continuity between child and adult psychiatry. On the other hand, prospective studies will be needed to verify the clinical significance of subthreshold forms [107 - 109] as well as the potential predictive value of subthreshold conditions and their impact in terms of public health.

\section{LIST OF ABBREVIATIONS}

$\begin{array}{lll}\text { AD } & = & \text { Asperger's Disorder } \\ \text { AdAS } & = & \text { Adult Autism Spectrum } \\ \text { ADHD } & = & \text { Attention Deficit Hyperactivity Disorders } \\ \text { ASD } & = & \text { Autism Spectrum Disorder } \\ \text { DSM-III } & = & \text { Diagnostic and Statistical Manual of Mental Disorders, 3rd edition } \\ \text { DSM-IV } & = & \text { Diagnostic and Statistical Manual of Mental Disorders, 4rd edition } \\ \text { DSM-5 } & = & \text { Diagnostic and Statistical Manual of Mental Disorders, } 5 \mathrm{ft} \text { edition } \\ \text { OCD } & = & \text { Obsessive-Compulsive Disorder } \\ \text { PTSD } & = & \text { Post Traumatic Stress Disorder }\end{array}$

\section{CONFLICT OF INTEREST}

The authors confirm that this article content has no conflict of interest.

\section{ACKNOWLEDGEMENTS}

Declared none.

\section{REFERENCES}

[1] Diagnostic and Statistical Manual of Mental Disorders, DSM-IV. $4^{\text {th }}$ ed. Washington, DC: American Psychiatric Press 1994.

[2] Diagnostic and Statistical Manual of Mental Disorders. $5^{\text {th }}$ ed. Arlington: American Psychiatric Association 2013.

[3] Sonuga-Barke EJ. 'What's up, (R)DoC?'--can identifying core dimensions of early functioning help us understand, and then reduce, developmental risk for mental disorders? J Child Psychol Psychiatry 2014; 55(8): 849-51. [http://dx.doi.org/10.1111/jcpp.12293] [PMID: 25039570]

[4] Doernberg E, Hollander E. Neurodevelopmental Disorders (ASD and ADHD): DSM-5, ICD-10, and ICD-11. CNS Spectr 2016; 21(4): 295-9. [http://dx.doi.org/10.1017/S1092852916000262] [PMID: 27364515]

[5] Takara K, Kondo T. Autism spectrum disorder among first-visit depressed adult patients: diagnostic clues from backgrounds and past history. Gen Hosp Psychiatry 2014; 36(6): 737-42.

[http://dx.doi.org/10.1016/j.genhosppsych.2014.08.004] [PMID: 25217491]

[6] Dell'Osso L, Dalle Luche R, Maj M. Adult Autism Spectrum as a transnosographic dimension. CNS Spectr 2015; 9: 1-3. [PMID: 26349624] 
[7] Frank E, Cassano GB, Shear MK, et al. The spectrum model: a more coherent approach to the complexity of psychiatric symptomatology. CNS Spectr 1998; 3: 23. [http://dx.doi.org/10.1017/S1092852900005836]

[8] Cassano GB, Dell'Osso L, Frank E, et al. The bipolar spectrum: a clinical reality in search of diagnostic criteria and an assessment methodology. J Affect Disord 1999; 54(3): 319-28. [http://dx.doi.org/10.1016/S0165-0327(98)00158-X] [PMID: 10467978]

[9] Insel TR. Rethinking schizophrenia. Nature 2010; 468(7321): 187-93. [http://dx.doi.org/10.1038/nature09552] [PMID: 21068826]

[10] Doherty JL, Owen MJ. Genomic insights into the overlap between psychiatric disorders: implications for research and clinical practice. Genome Med 2014; 6(4): 29. [http://dx.doi.org/10.1186/gm546] [PMID: 24944580]

[11] Asperger H. Die “autistischen Psychopathen” im kindesalter. Arch Psychiatr Nervenkr 1944; $117: 76$. [http://dx.doi.org/10.1007/BF01837709]

[12] Kanner L. Autistic disturbances of affective contact. Nerv Child 1943; 2: 217.

[13] Kanner L. The specificity of early infantile autism. Z Kinderpsychiatr 1958; 25(1-2): 108-13. [PMID: 24544881]

[14] Wing L. Asperger's syndrome: a clinical account. Psychol Med 1981; 11(1): 115-29. [http://dx.doi.org/10.1017/S0033291700053332] [PMID: 7208735]

[15] Frith U, Morton J, Leslie AM. The cognitive basis of a biological disorder: autism. Trends Neurosci 1991; 14(10): 433-8. [http://dx.doi.org/10.1016/0166-2236(91)90041-R] [PMID: 1722361]

[16] Bleuler E. Dementia Praecox oder Gruppe der Schizophrenien. In: Aschaffenburg A, Ed. Handbuch der Psychiatrie Spez Teil Abt, 1 Hälfte. Leipzig und Wien: Franz Deuticke 1911; 1: p. 420.

[17] Asperger H. [On the differential diagnosis of early infantile autism]. Acta Paedopsychiatr 1968; 35(4): 136-45. [PMID: 4880461]

[18] Ostwald PF. Musical behavior in early childhood. Dev Med Child Neurol 1973; 15(3): 367-75. [http://dx.doi.org/10.1111/j.1469-8749.1973.tb04897.x] [PMID: 4718692]

[19] James I. Asperger's Syndrome and High Achievment: Some very remarkable people. London: Jessica Kingsley Publishers 2005.

[20] Fitzgerald M. Misdiagnosis of Asperger syndrome as anankastic personality disorder. Autism 2002; 6(4): 435. [http://dx.doi.org/10.1177/1362361302006004010] [PMID: 12540134]

[21] Fitzgerald M. Creativity Psychosis Autism and the Social Brain. In: Reza-Mohammad M, Ed. A comprehensive Book on Autism Spectrum Disorders. Rijeka, In Tech 2011; p. 213. [http://dx.doi.org/10.5772/17439]

[22] Baron-Cohen S, Wheelwright S, Skinner R, Martin J, Clubley E. The autism-spectrum quotient (AQ): evidence from Asperger syndrome/high-functioning autism, males and females, scientists and mathematicians. J Autism Dev Disord 2001; 31(1): 5-17. [http://dx.doi.org/10.1023/A:1005653411471] [PMID: 11439754]

[23] Fitzgerald K, Hyman M, Swift K. Autism spectrum disorders. Glob Adv Health Med 2012; 1(4): 62-74. [http://dx.doi.org/10.7453/gahmj.2012.1.4.010] [PMID: 24278834]

[24] Frith U. A new look at language and communication in autism. Br J Disord Commun 1989; 24(2): 123-50. [http://dx.doi.org/10.3109/13682828909011952] [PMID: 2690916]

[25] Baron-Cohen S, Richler J, Bisarya D, Gurunathan N, Wheelwright S. The systemizing quotient: an investigation of adults with Asperger syndrome or high-functioning autism, and normal sex differences. Philos Trans R Soc Lond B Biol Sci 2003; 358(1430): 361-74. [http://dx.doi.org/10.1098/rstb.2002.1206] [PMID: 12639333]

[26] Lyons V, Fitzgerald M. Early memory and autism. J Autism Dev Disord 2005; 35(5): 683. [http://dx.doi.org/10.1007/s10803-005-0012-y] [PMID: 16175314]

[27] Doobay AF, Foley-Nicpon M, Ali SR, Assouline SG. Cognitive, adaptive, and psychosocial differences between high ability youth with and without autism spectrum disorder. J Autism Dev Disord 2014; 44(8): 2026-40. [http://dx.doi.org/10.1007/s10803-014-2082-1] [PMID: 24584434]

[28] Schopler E, Mesibov G, Baker A. Evaluation of treatment for autistic children and their parents. J Am Acad Child Psychiatry 1982; 21(3): 262-7. [http://dx.doi.org/10.1016/S0002-7138(09)60881-5] [PMID: 7096846]

[29] Klin A, Volkmar FR, Sparrow SS. Autistic social dysfunction: some limitations of the theory of mind hypothesis. J Child Psychol Psychiatry 1992; 33(5): 861-76. [http://dx.doi.org/10.1111/j.1469-7610.1992.tb01961.x] [PMID: 1378847]

[30] Eisenmajer R, Prior M, Leekam S, et al. Delayed language onset as a predictor of clinical symptoms in pervasive developmental disorders. J Autism Dev Disord 1998; 28(6): 527-33. 
[http://dx.doi.org/10.1023/A:1026004212375] [PMID: 9932239]

[31] Gillberg C. Asperger syndrome and high-functioning autism. Br J Psychiatry 1998; 172: $200-9$. [http://dx.doi.org/10.1192/bjp.172.3.200] [PMID: 9614468]

[32] Macintosh KE, Dissanayake C. Annotation: The similarities and differences between autistic disorder and Asperger's disorder: a review of the empirical evidence. J Child Psychol Psychiatry 2004; 45(3): 421-34. [http://dx.doi.org/10.1111/j.1469-7610.2004.00234.x] [PMID: 15055363]

[33] Klin A, Pauls D, Schultz R, Volkmar F. Three diagnostic approaches to Asperger syndrome: implications for research. J Autism Dev Disord 2005; 35(2): 221-34.

[http://dx.doi.org/10.1007/s10803-004-2001-y] [PMID: 15909408]

[34] Sanders JL. Qualitative or quantitative differences between Asperger's disorder and autism? Historical considerations. J Autism Dev Disord 2009; 39(11): 1560-7.

[http://dx.doi.org/10.1007/s10803-009-0798-0] [PMID: 19548078]

[35] Sharma S, Woolfson LM, Hunter SC. Confusion and inconsistency in diagnosis of Asperger syndrome: a review of studies from 1981 to 2010. Autism 2012; 16(5): 465-86.

[http://dx.doi.org/10.1177/1362361311411935] [PMID: 21810909]

[36] Nemeroff CB, Weinberger D, Rutter M, et al. DSM-5: a collection of psychiatrist views on the changes, controversies, and future directions. BMC Med 2013; 11: 202.

[http://dx.doi.org/10.1186/1741-7015-11-202] [PMID: 24229007]

[37] Mattila ML, Kielinen M, Linna SL, et al. Autism spectrum disorders according to DSM-IV-TR and comparison with DSM-5 draft criteria: an epidemiological study. J Am Acad Child Adolesc Psychiatry 2011; 50(6): 583-592.e11. [http://dx.doi.org/10.1016/j.jaac.2011.04.001] [PMID: 21621142]

[38] Huerta M, Bishop SL, Duncan A, Hus V, Lord C. Application of DSM-5 criteria for autism spectrum disorder to three samples of children with DSM-IV diagnoses of pervasive developmental disorders. Am J Psychiatry 2012; 169(10): 1056-64. [http://dx.doi.org/10.1176/appi.ajp.2012.12020276] [PMID: 23032385]

[39] Gibbs V, Aldridge F, Chandler F, Witzlsperger E, Smith K. Brief report: an exploratory study comparing diagnostic outcomes for autism spectrum disorders under DSM-IV-TR with the proposed DSM-5 revision. J Autism Dev Disord 2012; 42(8): $1750-6$. [http://dx.doi.org/10.1007/s10803-012-1560-6] [PMID: 22677932]

[40] Helles A, Gillberg CI, Gillberg C, Billstedt E. Asperger syndrome in males over two decades: stability and predictors of diagnosis. J Child Psychol Psychiatry 2015; 56(6): 711-8. [http://dx.doi.org/10.1111/jcpp.12334] [PMID: 25283685]

[41] Kim YS, Fombonne E, Koh YJ, Kim SJ, Cheon KA, Leventhal BL. A comparison of DSM-IV pervasive developmental disorder and DSM-5 autism spectrum disorder prevalence in an epidemiologic sample. J Am Acad Child Adolesc Psychiatry 2014; 53(5): 500-8. [http://dx.doi.org/10.1016/j.jaac.2013.12.021] [PMID: 24745950]

[42] Miller J. DSM-5 and autism spectrum disorders: the changes you haven't heard about yet. J Clin Psychiatry 2014; 75(11): e1326-7. [http://dx.doi.org/10.4088/JCP.13108933] [PMID: 25470101]

[43] Lai MC, Lombardo MV, Chakrabarti B, Baron-Cohen S. Subgrouping the autism "spectrum”: reflections on DSM-5. PLoS Biol 2013; 11(4): e1001544.

[http://dx.doi.org/10.1371/journal.pbio.1001544] [PMID: 23630456]

[44] Stewart ME, Barnard L, Pearson J, Hasan R, O’Brien G. Presentation of depression in autism and Asperger syndrome: a review. Autism 2006; 10(1): 103-16. [http://dx.doi.org/10.1177/1362361306062013] [PMID: 16522713]

[45] Skokauskas N, Gallagher L. Psychosis, affective disorders and anxiety in autistic spectrum disorder: prevalence and nosological considerations. Psychopathology 2010; 43(1): 8-16. [http://dx.doi.org/10.1159/000255958] [PMID: 19893339]

[46] Vannucchi G, Masi G, Toni C, Dell'Osso L, Marazziti D, Perugi G. Clinical features, developmental course, and psychiatric comorbidity of adult autism spectrum disorders. CNS Spectr 2014; 19(2): 157-64. [http://dx.doi.org/10.1017/S1092852913000941] [PMID: 24352005]

[47] Kato K, Mikami K, Akama F, et al. Clinical features of suicide attempts in adults with autism spectrum disorders. Gen Hosp Psychiatry 2013; 35(1): 50-3. [http://dx.doi.org/10.1016/j.genhosppsych.2012.09.006] [PMID: 23141028]

[48] Takara K, Kondo T. Comorbid atypical autistic traits as a potential risk factor for suicide attempts among adult depressed patients: a casecontrol study. Ann Gen Psychiatry 2014; 13(1): 33. [http://dx.doi.org/10.1186/s12991-014-0033-z] [PMID: 25328535]

[49] Le Couteur A, Bailey A, Goode S, et al. A broader phenotype of autism: the clinical spectrum in twins. J Child Psychol Psychiatry 1996; 37(7): 785-801. [http://dx.doi.org/10.1111/j.1469-7610.1996.tb01475.x] [PMID: 8923222]

[50] Duvall JA, Lu A, Cantor RM, Todd RD, Constantino JN, Geschwind DH. A quantitative trait locus analysis of social responsiveness in 
multiplex autism families. Am J Psychiatry 2007; 164(4): 656-62. [Erratum in: Am J Psychiatry. 2007;164:980]. [http://dx.doi.org/10.1176/ajp.2007.164.4.656] [PMID: 17403980]

[51] St Pourcain B, Wang K, Glessner JT, et al. Association between a high-risk autism locus on 5 p14 and social communication spectrum phenotypes in the general population. Am J Psychiatry 2010; 167(11): 1364-72. [http://dx.doi.org/10.1176/appi.ajp.2010.09121789] [PMID: 20634369]

[52] Constantino JN, Zhang Y, Frazier T, Abbacchi AM, Law P. Sibling recurrence and the genetic epidemiology of autism. Am J Psychiatry 2010; 167(11): 1349-56

[http://dx.doi.org/10.1176/appi.ajp.2010.09101470] [PMID: 20889652]

[53] Levy Y, Bar-Yuda C. Language performance in siblings of nonverbal children with autism. Autism 2011; 15(3): 341-54 [http://dx.doi.org/10.1177/1362361310386504] [PMID: 21363870]

[54] Lundström S, Chang Z, Råstam M, et al. Autism spectrum disorders and autistic like traits: similar etiology in the extreme end and the normal variation. Arch Gen Psychiatry 2012; 69(1): 46-52.

[http://dx.doi.org/10.1001/archgenpsychiatry.2011.144] [PMID: 22213788]

[55] Piven J, Palmer P, Jacobi D, Childress D, Arndt S. Broader autism phenotype: evidence from a family history study of multiple-incidence autism families. Am J Psychiatry 1997; 154(2): 185-90. [http://dx.doi.org/10.1176/ajp.154.2.185] [PMID: 9016266]

[56] Constantino JN, Lajonchere C, Lutz M, et al. Autistic social impairment in the siblings of children with pervasive developmental disorders. Am J Psychiatry 2006; 163(2): 294-6. [http://dx.doi.org/10.1176/appi.ajp.163.2.294] [PMID: 16449484]

[57] Scheeren AM, Stauder JE. Broader autism phenotype in parents of autistic children: reality or myth? J Autism Dev Disord 2008; 38(2): 276-87.

[http://dx.doi.org/10.1007/s10803-007-0389-x] [PMID: 17588199]

[58] Losh M, Adolphs R, Poe MD, et al. Neuropsychological profile of autism and the broad autism phenotype. Arch Gen Psychiatry 2009; 66(5): 518-26. [http://dx.doi.org/10.1001/archgenpsychiatry.2009.34] [PMID: 19414711]

[59] Wheelwright S, Auyeung B, Allison C, Baron-Cohen S. Defining the broader, medium and narrow autism phenotype among parents using the Autism Spectrum Quotient (AQ). Mol Autism 2010; 1(1): 10 [http://dx.doi.org/10.1186/2040-2392-1-10] [PMID: 20678260]

[60] Sucksmith E, Roth I, Hoekstra RA. Autistic traits below the clinical threshold: re-examining the broader autism phenotype in the $21^{\text {st }}$ century. Neuropsychol Rev 2011; 21(4): 360-89. [http://dx.doi.org/10.1007/s11065-011-9183-9] [PMID: 21989834]

[61] Taylor LJ, Maybery MT, Wray J, Ravine D, Hunt A, Whitehouse AJ. Brief report: do the nature of communication impairments in autism spectrum disorders relate to the broader autism phenotype in parents? J Autism Dev Disord 2013; 43(12): $2984-9$. [http://dx.doi.org/10.1007/s10803-013-1838-3] [PMID: 23619954]

[62] De la Marche W, Noens I, Luts J, Scholte E, Van Huffel S, Steyaert J. Quantitative autism traits in first degree relatives: evidence for the broader autism phenotype in fathers, but not in mothers and siblings. Autism 2012; 16(3): 247-60. [http://dx.doi.org/10.1177/1362361311421776] [PMID: 21949002]

[63] Sucksmith E, Allison C, Baron-Cohen S, Chakrabarti B, Hoekstra RA. Empathy and emotion recognition in people with autism, first-degree relatives, and controls. Neuropsychologia 2013; 51(1): 98-105. [http://dx.doi.org/10.1016/j.neuropsychologia.2012.11.013] [PMID: 23174401]

[64] Berthoz S, Lalanne C, Crane L, Hill EL. Investigating emotional impairments in adults with autism spectrum disorders and the broader autism phenotype. Psychiatry Res 2013; 208(3): 257-64. [http://dx.doi.org/10.1016/j.psychres.2013.05.014] [PMID: 23747233]

[65] Levin-Decanini T, Maltman N, Francis SM, et al. Parental broader autism subphenotypes in ASD affected families: relationship to gender, child's symptoms, SSRI treatment, and platelet serotonin. Autism Res 2013; 6(6): 621-30. [http://dx.doi.org/10.1002/aur.1322] [PMID: 23956104]

[66] Ozonoff S, Young GS, Belding A, et al. The broader autism phenotype in infancy: when does it emerge? J Am Acad Child Adolesc Psychiatry 2014; 53(4): 398-407.e2. [http://dx.doi.org/10.1016/j.jaac.2013.12.020] [PMID: 24655649]

[67] Cooper SA, Smiley E, Morrison J, et al. Psychosis and adults with intellectual disabilities. Prevalence, incidence, and related factors. Soc Psychiatry Psychiatr Epidemiol 2007; 42(7): 530-6. [http://dx.doi.org/10.1007/s00127-007-0197-9] [PMID: 17502974]

[68] Hutton J, Goode S, Murphy M, Le Couteur A, Rutter M. New-onset psychiatric disorders in individuals with autism. Autism 2008; 12(4): $373-90$ [http://dx.doi.org/10.1177/1362361308091650] [PMID: 18579645]

[69] Mouridsen SE, Rich B, Isager T. Psychiatric disorders in adults diagnosed as children with atypical autism. A case control study. J Neural Transm (Vienna) 2008; 115(1): 135-8. [http://dx.doi.org/10.1007/s00702-007-0798-1] [PMID: 17768593] 
[70] Tsiouris JA, Kim SY, Brown WT, Cohen IL. Association of aggressive behaviours with psychiatric disorders, age, sex and degree of intellectual disability: a large-scale survey. J Intellect Disabil Res 2011; 55(7): 636-49. [http://dx.doi.org/10.1111/j.1365-2788.2011.01418.x] [PMID: 21492292]

[71] Nylander I. A 20-year prospective follow-up study of 2164 cases at the child guidance clinics in Stockholm. Acta Paediatr Scand Suppl 1979; 276: $1-45$. [PMID: 291297]

[72] Maj M. "Psychiatric comorbidity": an artefact of current diagnostic systems? Br J Psychiatry 2005; $186: 182-4$. [http://dx.doi.org/10.1192/bjp.186.3.182] [PMID: 15738496]

[73] Dell'Osso L, Pini S. What did we learn from research on comorbidity in psychiatry? Advantages and limitations in the forthcoming DSM-V era. Clin Pract Epidemol Ment Health 2012; 8: 180-4. [http://dx.doi.org/10.2174/1745017901208010180] [PMID: 23304235]

[74] Diagnostic and Statistical Manual of Mental Disorders, DSM-III. $3^{\text {rd }}$ ed. Washington, DC: American Psychiatric Press 1980.

[75] Maj M. The self and schizophrenia: some open issues. World Psychiatry 2012; 11(2): 65-6. [http://dx.doi.org/10.1016/j.wpsyc.2012.05.001] [PMID: 22654929]

[76] Minkowski E. La Schizophrenie: psychopathologie des schizoides et des schizophrenes. Paris: Payot 1927.

[77] Blankenburg W. Der verlust der naturlichen Selbstverstandlichkeit. Berlin: Springer 1971.

[78] Parnas J, Bovet P. Autism in schizophrenia revisited. Compr Psychiatry 1991; 32(1): 7-21. [http://dx.doi.org/10.1016/0010-440X(91)90065-K] [PMID: 2001623]

[79] Parnas J. A disappearing heritage: the clinical core of schizophrenia. Schizophr Bull 2011; 37(6): 1121-30 [http://dx.doi.org/10.1093/schbul/sbr081] [PMID: 21771902]

[80] Gross G. The onset of schizophrenia. Schizophr Res 1997; 28(2-3): 187-98. [http://dx.doi.org/10.1016/S0920-9964(97)00118-7] [PMID: 9468353]

[81] Dalle Luche R. Psychotic and hysterical dissociative syndromes. Neurol Psychiatry Brain Res 2002; 10(2): 83.

[82] Bolinskey PK, James AV, Cooper-Bolinskey D, et al. Revisiting the blurry boundaries of schizophrenia: Spectrum disorders in psychometrically identified schizotypes. Psychiatry Res 2015; 225(3): 335-40.

[83] Fagiolini A, Dell'osso L, Pini S, et al. Validity and reliability of a new instrument for assessing mood symptomatology: the Structured Clinical Interview for Mood Spectrum (SCIMOODS). Int J Meth Psy 1999; 8: 71. [http://dx.doi.org/10.1002/mpr.58]

[84] Shear MK, Frank E, Rucci P, et al. Panic-agoraphobic spectrum: reliability and validity of assessment instruments. J Psychiatr Res 2001; 35(1): 59-66.

[http://dx.doi.org/10.1016/S0022-3956(01)00002-4] [PMID: 11287057]

[85] Sbrana A, Dell'Osso L, Benvenuti A, et al. The psychotic spectrum: validity and reliability of the Structured Clinical Interview for the Psychotic Spectrum. Schizophr Res 2005; 75(2-3): 375-87. [http://dx.doi.org/10.1016/j.schres.2004.09.016] [PMID: 15885528]

[86] Dell'Osso L, Armani A, Rucci P, et al. Measuring mood spectrum: comparison of interview (SCI-MOODS) and self-report (MOODS-SR) instruments. Compr Psychiatry 2002; 43(1): 69-73. [http://dx.doi.org/10.1053/comp.2002.29852] [PMID: 11788923]

[87] Dell'Osso L, Rucci P, Cassano GB, et al. Measuring social anxiety and obsessive-compulsive spectra: comparison of interviews and selfreport instruments. Compr Psychiatry 2002; 43(2): 81-7.

[http://dx.doi.org/10.1053/comp.2002.30795] [PMID: 11893984]

[88] Dell'Osso L, Shear MK, Carmassi C, et al. Validity and reliability of the Structured Clinical Interview for the Trauma and Loss Spectrum (SCI-TALS). Clin Pract Epidemol Ment Health 2008; 4: 2. [http://dx.doi.org/10.1186/1745-0179-4-2] [PMID: 18226228]

[89] Cassano GB, Banti S, Mauri M, et al. Internal consistency and discriminant validity of the Structured Clinical Interview for Panic Agoraphobic Spectrum (SCI-PAS). Int J Methods Psychiatr Res 1999; 8: 138 [http://dx.doi.org/10.1002/mpr.64]

[90] Dell'Osso L, Carmassi C, Rucci P, et al. A multidimensional spectrum approach to post-traumatic stress disorder: comparison between the Structured Clinical Interview for Trauma and Loss Spectrum (SCI-TALS) and the Self-Report instrument (TALS-SR). Compr Psychiatry 2009; 50(5): 485-90. [http://dx.doi.org/10.1016/j.comppsych.2008.11.006] [PMID: 19683620]

[91] Dell'Osso L, Gesi C, Massimetti E, et al. Autism subthreshold spectrum (AdAS spectrum): Validation of a questionnaire investigating subthreshold autism spectrum. Compr Psychiatry [in press].

[92] Attwood T. Understanding and managing circumscribed interests. In: Prior M, Ed. Learning and behavior problems in Asperger syndrome. New York: The Guilford Press 2003.

[93] Ray F, Marks C, Bray-Garretson H. Challenges to treating adolescents with Asperger's syndrome who are sexually abusive. Sex Addict 
Compulsivity 2009; 11: 265.

[http://dx.doi.org/10.1080/10720160490900614]

[94] Dell'Osso L, Dalle Luche R, Cerliani C, et al. Unexpected autism spectrum symptoms in a 25-year-old male stalker hospitalized for delusional disorder: a case report. Compr Psychiatry 2015; 61: 10-4. [http://dx.doi.org/10.1016/j.comppsych.2015.04.003] [PMID: 26031384]

[95] Dougherty CC, Evans DW, Myers SM, Moore GJ, Michael AM. A comparison of structural brain imaging findings in autism spectrum disorder and attention-deficit hyperactivity disorder. Neuropsychol Rev 2016; 26(1): 25-43. [http://dx.doi.org/10.1007/s11065-015-9300-2] [PMID: 26482248]

[96] Grove R, Baillie A, Allison C, Baron-Cohen S, Hoekstra RA. Empathizing, systemizing, and autistic traits: latent structure in individuals with autism, their parents, and general population controls. J Abnorm Psychol 2013; 122(2): 600-9. [http://dx.doi.org/10.1037/a0031919] [PMID: 23713510]

[97] Hofvander B, Delorme R, Chaste P, et al. Psychiatric and psychosocial problems in adults with normal-intelligence autism spectrum disorders. BMC Psychiatry 2009; 9: 35. [http://dx.doi.org/10.1186/1471-244X-9-35] [PMID: 19515234]

[98] Lugnegård T, Hallerbäck MU, Gillberg C. Psychiatric comorbidity in young adults with a clinical diagnosis of Asperger syndrome. Res Dev Disabil 2011;32(5): 1910-7.

[http://dx.doi.org/10.1016/j.ridd.2011.03.025] [PMID: 21515028]

[99] Oldershaw A, Treasure J, Hambrook D, Tchanturia K, Schmidt U. Is anorexia nervosa a version of autism spectrum disorders? Eur Eat Disord Rev 2011; 19(6): 462-74.

[http://dx.doi.org/10.1002/erv.1069] [PMID: 21280165]

[100] Dell'Osso L, Abelli M, Carpita B, et al. Historical evolution of the concept of qnorexia nervosa and relationships with orthorexia nervosa, autism and obsessive- compulsive spectrum. Neuropsychiatr Dis Treat 2016; 12: 1651-60. [http://dx.doi.org/10.2147/ntd.s 108912]

[101] Kamio Y, Moriwaki A, Takei R, et al. Psychiatric issues of children and adults with autism spectrum disorders who remain undiagnosed. Seishin Shinkeigaku Zasshi 2013; 115(6): 601-6. [PMID: 23944117]

[102] Simoncini M, Miniati M, Vanelli F, et al. Lifetime Autism Spectrum features in a patient with a Psychotic Mixed Episode Who Attempted Suicide. Case Rep Psychiatry 2014; 2014: 459-524. [http://dx.doi.org/10.1155/2014/459524]

[103] Dell'Osso L, Dalle Luche R, Carmassi C. A new perspective in post-traumatic stress disorder: which role for unrecognized autism spectrum? Int J Emerg Ment Health 2015; 17: e188.

[104] Skeppar P, Adolfsson R. Bipolar II and the bipolar spectrum. Nord J Psychiatry 2006; 60(1): 7-26. [http://dx.doi.org/10.1080/08039480500504685] [PMID: 16500795]

[105] King R. Complex Post-Traumatic Stress Disorder: implications for individuals with Autism Spectrum Disorders- Part 1. J Dev Disabil 2010; 16: 91 .

[106] Tantam D, Girgis S. Recognition and treatment of Asperger syndrome in the community. Br Med Bull 2009; 89: 41-62. [http://dx.doi.org/10.1093/bmb/ldp006] [PMID: 19240041]

[107] Gesi C, Carmassi C, Miniati M, et al. Psychotic spectrum symptoms across the lifespan are related to lifetime suicidality among 147 patients with bipolar or major depressive disorder. Ann Gen Psychiatry 2016; $21: 15$. [http://dx.doi.org/10.1186/s12991-016-0101-7]

[108] Billeci L, Calderoni S, Conti E, et al. The broad autism (endo)phenotype: neurostructural and neurofunctional correlates in parents of individuals with autism spectrum disorders. Front Neurosci 2016; 10: 346. [http://dx.doi.org/10.3389/FNINS.2016.00346]

[109] Dell'Osso L, Gesi C, Carmassi C. Suicide and autism spectrum disorders: The role of trauma J Psychopatol 2016; $107-9$.

(C) Dell'Osso et al.; Licensee Bentham Open

This is an open access articles licensed under the terms of the Creative Commons Attribution-Non-Commercial 4.0 International Public License (CC BY-NC 4.0) (https://creativecommons.org/licenses/by-nc/4.0/legalcode), which permits unrestricted, non-commercial use, distribution and reproduction in any medium, provided that the work is properly cited. 